Goldschmidt 2021 Abstract

https://doi.org/10.7185/gold2021.4203

\section{Hydrothermal REE fluid-mineral reaction paths in critical mineral deposits ALEXANDER GYSI}

New Mexico Tech

Presenting Author: alexander.gysi@nmt.edu

Critical mineral deposits commonly form in magmatichydrothermal systems including carbonatites and alkaline syenites, or evolved peralkaline granites where the rare earth element (REE) undergo a complex array of partitioning, transport and mineralization. Significant alteration and veining zones develop in these deposits and can be used to vector ore zones in the field [1]. The REE minerals typically reflect the characteristics of these systems, which are enriched in carbonate, fluoride, and phosphate or a combination thereof. The REE can also be incorporated into vein minerals such as calcite, fluorite and apatite where the $\mathrm{REE}^{3+}$ exchange for $\mathrm{Ca}^{2+}$ on the crystal lattice [2]. These minerals give us clues about the hydrothermal reaction paths of REE in critical mineral deposits. This study aims to: 1) present our recent findings from hydrothermal fluid-mineral REE partitioning experiments, 2) discuss thermodynamic models to simulate REE in critical mineral deposits, and 3) link the thermodynamic simulations to field observations.

Hydrothermal fluid-calcite partitioning experiments were conducted between 100 and $200{ }^{\circ} \mathrm{C}$ by hydrothermal fluid mixing and precipitation [2] at near neutral to mildly alkaline $\mathrm{pH}(6-9)$. The REE concentrations in synthetic calcite crystals and aqueous fluids sampled in situ were used to fit the data to the lattice strain model [3] and using the Dual Thermodynamic approach [4]. A second type of experiment consisted of reacting natural fluorite and apatite crystals with acidic to mildly acidic ( $\mathrm{pH}$ of $2-4$ ) aqueous fluids in batch-type reactors to study the behavior of REE and mineral dissolution-precipitation reactions near crystal surfaces. The GEMS code package [5] was used to implement these new data into a thermodynamic model and simulate possible REE reaction paths in hydrothermal fluids. Two REE mineral deposits in New Mexico (Lemitar and Gallinas Mountains) present ideal case studies to illustrate how these models can be linked to field observations from natural systems.

[1] Gysi et al. (2016), Econ. Geol. 111, 1241-1276; [2] Perry and Gysi (2020), Geochim. Cosmochim. Acta 286, 177-197; [3] Blundy and Wood (1994) Nature 372, 452454; [4] Kulik (2006), Chem. Geol. 225, 189-212; [5] Kulik et al. (2013), Computat. Geosci. 17, 1-24.

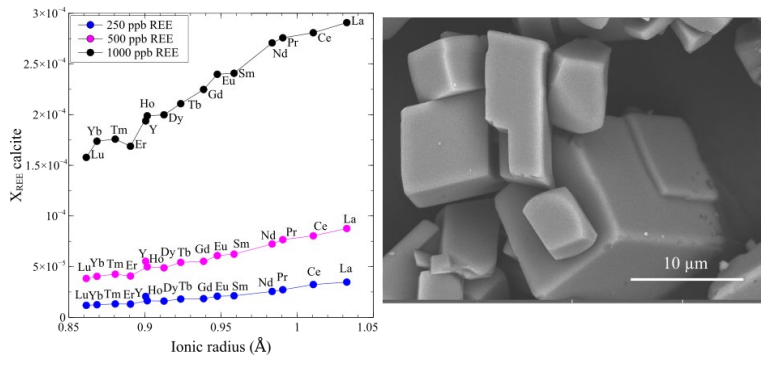

